\title{
Barriers and facilitating communication skills for breaking bad news: from the specialists' practice perspective*
}

\author{
Enna Catalina Payán, Psychol ${ }^{1}$, David Andrés Montoya, Psychol ${ }^{2}$, \\ John Jairo Vargas, MD ${ }^{3}$, María Clara Vélez, Social Worker ${ }^{4}$, \\ Alfonso Castaño, Nurse ${ }^{4}$, Alicia Krikorian, Psychol ${ }^{4}$
}

\section{SUMMARY}

Introduction: Breaking bad news is one of a physician's most difficult duties. There are several studies related to the patient's needs, but few reflect on the doctors' experience.

Materials and method: A descriptive, cross-sectional research was carried out to study issues related to the process of delivering bad news which might act as barriers and facilitating skills from the doctor's point of view. These issues were identified through a self-administered survey.

Results: Participant doctors use different strategies to communicate bad news to their patients. Examples of these strategies are: to be familiar with the patients' medical history, to ensure that there is enough time, to know the patient's caregivers and/ or relatives, to determine the patient's level of knowledge about his/her condition, to use non-technical words, to give information in small pieces, to assess the patient's understanding, to devise a joint action plan, among others.

Conclusion: The communication barriers that were identified focused on the emotional issues of the communication process, particularly those related to the recognition of own emotions, and the limited training about communication strategies available to doctors. Consequently, there is a need to implement training programs that provide doctors with tools to facilitate the bad news communication process.

Keywords: Physician-patient communication; Barriers; Effective communication skills.

Barreras y facilitadores en la comunicación de malas noticias: Perspectiva desde la práctica de médicos especialistas

\section{RESUMEN}

Introducción: La comunicación de malas noticias es una de las tareas más difíciles que deben enfrentar los profesionales de la salud. Existen múltiples estudios acerca de las necesidades del paciente, pero pocos que tengan en cuenta la experiencia de los médicos.

Materiales y método: Se realizó una investigación descriptiva, transversal para estudiar aspectos del proceso de comunicación de malas noticias que pueden actuar como barreras y facilitadores desde la percepción del médico; identificados por medio de una encuesta auto-aplicable.

Resultados: Los médicos participantes utilizan distintas estrategias durante la comunicación de malas noticias a sus pacientes como: conocer los detalles de la historia clínica, asegurarse de tener tiempo suficiente, conocer a los acompañantes e identificar cuánto sabe el paciente acerca de su situación, utilizar vocabulario sencillo, dar la información por partes, comprobar que el paciente esté comprendiendo, formular en conjunto un plan que se ha de seguir, entre otros.

Conclusiones: Las barreras comunicativas identificadas se centraron en los aspectos emocionales del proceso comunicativo, específicamente en lo relacionado con la identificación de emociones propias, y en la limitada formación que reciben

* Project funded by the Universidad Pontificia Bolivariana Integrated Center for Research and Development (CIDI)

1. Supporting Professor, Universidad Pontificia Bolivariana, Psychologist, Hospital Pablo Tobón Uribe, Medellín, Colombia. e-mail:catapayan@hotmail.com

2. The Children’s Neuro-psychology Center, Medellín, Colombia. e-mail: david-montoya@hotmail.com

3. Pain and Palliative Care Group Coordinator, Universidad Pontificia Bolivariana, Pain and Palliative Care specialist, Instituto de Cancerología, Medellín,Colombia.e-mail: sana@une.net.co

4. Professor and researcher of the Pain and Palliative Care Group, Universidad Pontificia Bolivariana, Medellín, Colombia. e-mail:maclavelez@gmail.com thomyork98@hotmail.com aliciakriko@hotmail.com

Received for publication December 3, 2007 Accepted for publication April 14, 2009 
los médicos en estrategias comunicativas, lo que genera la necesidad de implementar programas de capacitación que les brinden herramientas para facilitar el proceso de comunicación de malas noticias.

\section{Palabras clave: Comunicación médico-paciente; Barreras; Facilitadores.}

Delivering bad news may be one of the most difficult tasks faced by medical staff ${ }^{1}$, because this process can be very distressing and emotionally shocking for both the bearer and the recipient, as the latter hardly forgets where, when and how the bad news was conveyed ${ }^{2}$. Therefore, this task calls for the doctor to have training in specific strategies, bearing in mind that skills on this ground do not improve with time and clinical practice, but demand appropriate knowledge and learning ${ }^{3}$.

It is important to keep in mind that, although bad news are directly linked to the delivery of a serious disease diagnosis, it is not necessarily related to this particular time, but also to events such as: a chronic or disabling disease, the need of implementing a painful or demanding treatment or even the information received at a bad moment and that may be deemed as trivial by the doctor ${ }^{4}$. In this study the communication of bad news is defined as: «any information about the health care process where there is a feeling of hopelessness, perception of threat to a person's mental or physical state, risk of upsetting an established lifestyle, with little chance of facing the recent event objectively or subjectively» ${ }^{4-6}$.

Various studies have approached this situation. Nevertheless, research has mainly focused on the patient's experience and, a minimal number of the research studies barely consider the doctor's insight on his behaviors, feelings, and thoughts during the process of delivering bad news. Commonly, people have deep feelings at delivering or receiving bad news. Ptscek and Eberhardt ${ }^{5}$ recommend a model to understand the bad news related stress from the physician's and the patient's points of view. This model describes the stress experienced by doctors before communicating the bad news, and suggests that this feeling reaches the highest level during the clinical encounter, whereas the patient's highest level of stress usually happens some time after the conference has finished ${ }^{5}$.

In 2003, Alves de Lima ${ }^{1}$ stated that clinicians feel uncomfortable discussing unfavorable information. This is due not only to the fear of taking hope away from the patient, but also to the fear of the patient's and his/her relatives' reactions. Although the importance of not underestimating the patient's autonomy and empowerment has been demonstrated, many doctors adopt a paternalistic approach to avoid suffering in those who seek advice ${ }^{7-9}$.

Knowing that breaking bad news is one of the situations where the doctor's professionalism, vital experience and ability to gain trust are tested ${ }^{10}$ and that there is limited information regarding specific aspects of the bad news delivery process in Colombia, it is necessary to identify and describe the process barriers and effective communication skills, from the point of view of those specialists and sub-specialists working in several institutions in Medellín.

\section{MATERIALS AND METHOD}

Population. The study population involved specialists in oncologic surgery, clinical oncology, radiation therapy, oncologic pediatrics, internal medicine, critical medicine, nephrology, palliative care and cardiovascular surgery from 6 institutions located in Medellín, Colombia, chosen at wisdom. A total of 88 medical doctors who gave their verbal consent to participation were contacted, 82 (93.1\%) of them completed the survey. The remaining $6.9 \%$ did not return the instrument claiming lack of time for completion. Therefore, they were excluded from the study.

Procedure. A descriptive, cross-sectional research was carried out. Each institution director was contacted to facilitate specialists and/or sub-specialists participation. The Ethics Committee from the Universidad Pontificia Bolivariana and from each participating institution approved the study protocol. Each participant gave verbal consent and the confidentiality of the individual results was explained. Each doctor was asked to complete the survey individually. The way of completing the survey and the purpose of their participation were also explained. They had a 3-day deadline to answer and return the survey in a sealed envelope in order to guarantee privacy and improve participants' confidence.

Instrument. A survey was designed specifically for this study, including communication strategies and the factors that facilitate or hinder the breaking of bad news as it is described in the literature, and later validated by the experts' criterion. Two pilot tests were performed 
with specialists (who were not part of the final sample) to assess understanding and answers adaptation. The final survey included 11 questions with the following answer choices: 2 dichotomic answers, 9 likert Scales. Socio-demographic data (age, sex, marital status, specialty or sub-specialty and years of practice), variables related to the different stages of the bad news delivery process and other aspects that affect communication were studied:

Preparation: review medical history, privacy and adequate time, mental rehearsal, recording of relevant data, among others.

Analysis: Know the patient's care-givers and/or relatives, identify the patient's level of knowledge, determine how much he/she wants to know, and his/her emotional state, among others.

Communication: Use of non-technical words, give information in small pieces, asses understanding, use drawings, among others.

Emotional distress: emotional feelings identified by the doctor during the stages of the process

Education: training in effective communication skills mainly focused on breaking bad news organizational resources and their use. Barriers and facilitators were classified based on the so called inappropriate strategies (that hinder communication) and appropriate strategies (that facilitate communication). Refer to Table 1 for details on the process facilitating skills and barriers.

Analysis. The information was analyzed using SPSS 12.0 statistical package. Descriptive statistic for sociodemographic data and the study variables were generated.

\section{RESULTS}

The sample included 82 medical doctors from different specialties and sub-specialties working in 6 health care providing institutions. The average age was 40.26 (SD 9.2; age range: 27-64); and the average length of practice time was of 10.8 years (SD 8.2; range: $1-40$ ). Of the total sample, $84.1 \%$ were male and $63.4 \%$ were married, followed by $26.8 \%$ of unmarried participants. The results for each one of the studied aspects are described below, taking into account those bad news communication barriers and facilitators that were identified in each of the aspects:

Preparation. Of the total studied doctors, 78\% feel little or moderate uneasiness before disclosing the information, $93.9 \%$ prefer informing the bad news to their patients personally and $3.7 \%$ would choose a psychologist to be the bearer. Of the total number of participants, $67.1 \%$ assure preparing themselves before meeting the patient, whereas $32.9 \%$ do not prepare themselves. Among those who prepare themselves, $53.7 \%$, state that they review the details of the medical history in advance, $65.8 \%$ usually or always arrange for privacy, $37.8 \%$ always ensure having enough time available, 33\% usually or always rehearse mentally before the disclosure whereas $34.2 \%$ sometimes or never do it. 34.9\% assure that they sometimes or never record important data about the patient's information and only $4.9 \%$ always use this strategy.

Of the physicians, 22\% usually identify their own feelings before speaking to the patient, followed by $19.5 \%$ who sometimes identify them and $15.9 \%$ that never do it; $18.3 \%$ always assume that the significance of the bad news is the same for him/her as it is for the patient, $26.8 \%$ usually do it and only $9.8 \%$ believe that the patient may interpret data in a different way (Table 2).

Exploration. Of the doctors, $80.4 \%$ state that they always or usually know the patient's caregivers and/or relatives and their type of relationship; $67.1 \%$ determine the patients' level of knowledge about their disease while $28 \%$ usually verify this; $37.8 \%$ and $31.7 \%$ usually and always, respectively, know the patient's preferences regarding the information; 78\% identify the patient's feelings and $20.8 \%$ never or sometimes do it. Of the doctors, $54.9 \%$ state that they always reflect on the recipient's cultural and socio-economic aspects, and $39 \%$ usually do it (Table 2).

Communication strategies. Of the doctors, $68.3 \%$ ensure the use of non-technical words when they deliver bad news to their patients; $41.5 \%$ and $39.0 \%$ usually and always, respectively, give the information in small pieces; $54.9 \%$ always check that the patient understands the information; 39\% usually do it; 50\% of the participants usually and always use diagrams and drawings during the process; $51.2 \%$ usually strive to maintain balance among honesty, compassion and hope and $45.1 \%$ think that they always find it.

Of the studied doctors, 75\% always allow interruptions and 78\% tolerate the patient's silence and weeping at all times; $43.9 \%$ always encourage the patient to 


\section{Table 1}

Classification of facilitators and barriers in bad news communication

\section{Preparation:}

Familiarize with the patients' medical history

Arrange for privacy and avoid interruptions

\section{Ensure having enough time available}

Rehearse mentally before breaking the bad news

Jot down important data about what he/she should or should not disclose to his/her patient

Identify own emotions before disclosing the bad news

- Do not assume that the bad news have the same meaning for him/her as for the patient

\section{Exploration:}

- Know the patient's caregivers and/or relatives and their relationship

- Assess the patient's level of knowledge

- Identify the patient's emotions before receiving the bad news

- Acknowledge the patient's cultural and socio-economic characteristics

\section{Communication:}

Use straightforward language and avoid medical jargon

- Give information in small pieces

Always check the patient's understanding

Use diagrams and drawings

Strive to maintain a balance among honesty, compassion and hope

Allow the patient to interrupt

Tolerate and allow time for silence and weeping

Encourage the patient to express his/her emotions

Identify the patient's emotional reactions that require immediate attention

Ensure emotional support for the patient

Do not avoid using words such as death, cancer, terminal, chronic, degenerative disease, among others

Recognize own feelings when communicating bad news

Devise a joint action plan with the patient

Feelings (low scores in the following emotional experiences):

Anxiety

Fear

Sadness

Guilt

- Helplessness

- Frustration

\section{Training:}

- Know how to effectively disclose bad news to his/her patients

- Have formal training in communication skills to deliver bad news

- Have non-empirical professional training in emotional crises intervention

- Willing to be trained in communication skills

\section{Organizational characteristics:}

- Have enough time for his/her clinical practice

- The institution's space characteristics (privacy, comfort) are adequate

There is interdisciplinary support available in the institution where he/she works

Frequently use that support

The institution where he/she works offers support that allows doctors to deal with and handle emotions triggered from the bad news communication process

Note: High scores of the listed factors are deemed as facilitators in communicating bad news. Those that are not followed or available (low score) are seen as a barriers. High scores of listed emotions are regarded as barriers 
Table 2

Study variables including the preparation, exploration and communication stages of bad news communication for the studied population

\begin{tabular}{|c|c|c|c|c|c|}
\hline \multirow[t]{2}{*}{ Variable } & Never & Sometimes & Usually & Always & $\mathrm{N}^{\circ}$ data \\
\hline & N (\%) & N (\%) & N (\%) & N (\%) & N (\%) \\
\hline \multicolumn{6}{|l|}{ Preparation stage } \\
\hline $\begin{array}{l}\text { Familiarizes with the patients' } \\
\text { medical history* }\end{array}$ & - & - & $11(20.0)$ & $44(80.0)$ & - \\
\hline Arranges for privacy* & - & $1(1.2)$ & $27(32.9)$ & $27(32.9)$ & - \\
\hline $\begin{array}{l}\text { Ensures having enough time } \\
\text { available* }\end{array}$ & - & $2(2.4)$ & $22(26.8)$ & $31(37.8)$ & - \\
\hline Rehearses mentally* & $8(9.8)$ & $20(24.4)$ & $14(17.1)$ & $13(15.9)$ & - \\
\hline Jots down important data to tell* & $27(32.9)$ & $18(22)$ & $6(7.3)$ & $4(4.9)$ & - \\
\hline Identifies own emotions* & $13(15.9)$ & $16(19.5)$ & $18(22.0)$ & $8(9.8)$ & - \\
\hline $\begin{array}{l}\text { Assumes that importance is the same } \\
\text { for both* }\end{array}$ & $8(9.8)$ & $7(8.5)$ & $22(26.8)$ & $15(18.3)$ & - \\
\hline \multicolumn{6}{|l|}{ Exploration stage } \\
\hline $\begin{array}{l}\text { Knows the patient's caregivers and/or } \\
\text { relatives and their relationship }\end{array}$ & - & $15(18.3)$ & $33(40.2)$ & $33(40.2)$ & $1(1.2)$ \\
\hline $\begin{array}{l}\text { Assesses the patient's level of } \\
\text { knowledge }\end{array}$ & - & $3(3.7)$ & $23(28)$ & $55(67.1)$ & $1(1.2)$ \\
\hline $\begin{array}{l}\text { Identifies the patient's information } \\
\text { preferences }\end{array}$ & $3(3.7)$ & $21(25.6)$ & $31(37.8)$ & $26(31.7)$ & $1(1.2)$ \\
\hline Identifies the patient's emotions & $4(4.9)$ & $13(15.9)$ & $32(39.0)$ & $32(39)$ & $1(1.2)$ \\
\hline $\begin{array}{l}\text { Acknowledges cultural and socio- } \\
\text { economic aspects }\end{array}$ & $2(2.4)$ & $2(2.4)$ & $32(39.0)$ & $45(54.9)$ & $1(1.2)$ \\
\hline \multicolumn{6}{|l|}{ Communication stage } \\
\hline Uses straightforward language & $4(4.9)$ & $22(26.8)$ & $56(68.3)$ & & \\
\hline Gives information in small pieces & $1(1.2)$ & $14(17.1)$ & $34(41.5)$ & $32(39.0)$ & $1(1.2)$ \\
\hline Assesses patient's understanding & - & $5(6.1)$ & $32(39.0)$ & $45(54.9)$ & - \\
\hline Uses diagrams and drawings & $7(8.5)$ & $27(32.9)$ & $32(39.0)$ & $16(19.5)$ & - \\
\hline $\begin{array}{l}\text { Balances among honesty, } \\
\text { compassion and hope }\end{array}$ & - & $3(3.7)$ & $42(51.2)$ & $37(45.1)$ & - \\
\hline Allows the patient to interrupt & - & $1(1.2)$ & $19(23.2)$ & $62(75.6)$ & - \\
\hline Tolerates silence and weeping & - & - & $18(22.0)$ & $64(78.0)$ & - \\
\hline $\begin{array}{l}\text { Encourages the patient to express } \\
\text { emotions }\end{array}$ & $1(1.2)$ & $14(17.1)$ & $31(38.8)$ & $36(43.9)$ & - \\
\hline $\begin{array}{l}\text { Identifies the patient's feelings that } \\
\text { require immediate attention }\end{array}$ & $1(1.2)$ & $14(17.1)$ & $44(53.7)$ & $23(28)$ & - \\
\hline $\begin{array}{l}\text { Ensures that the patient gets } \\
\text { emotional support }\end{array}$ & $3(3.7)$ & $24(29.3)$ & $34(41.5)$ & $21(25.6)$ & - \\
\hline Recognizes his/her own emotions & $27(32.9)$ & $29(35.4)$ & $22(26.8)$ & $4(4.9)$ & - \\
\hline $\begin{array}{l}\text { Avoids using words such as cancer, } \\
\text { death, terminal illness, etc }\end{array}$ & $1(1.2)$ & $11(13.4)$ & $44(53.7)$ & $26(31.7)$ & - \\
\hline $\begin{array}{l}\text { Devises a joint action plan with the } \\
\text { patient }\end{array}$ & - & $4(4.9)$ & $22(26.8)$ & $56(68.3)$ & - \\
\hline
\end{tabular}

* Responses from the participants who considered themselves as being prepared to communicate bad news 


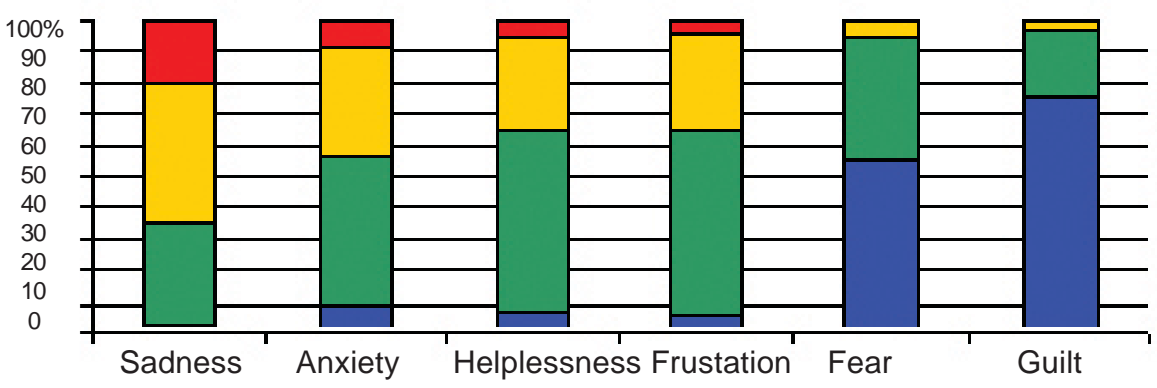

Graphic 1. Doctors' emotions during the process

Never $\square$ :Sometimes $\square$ Usually $\square$ Always

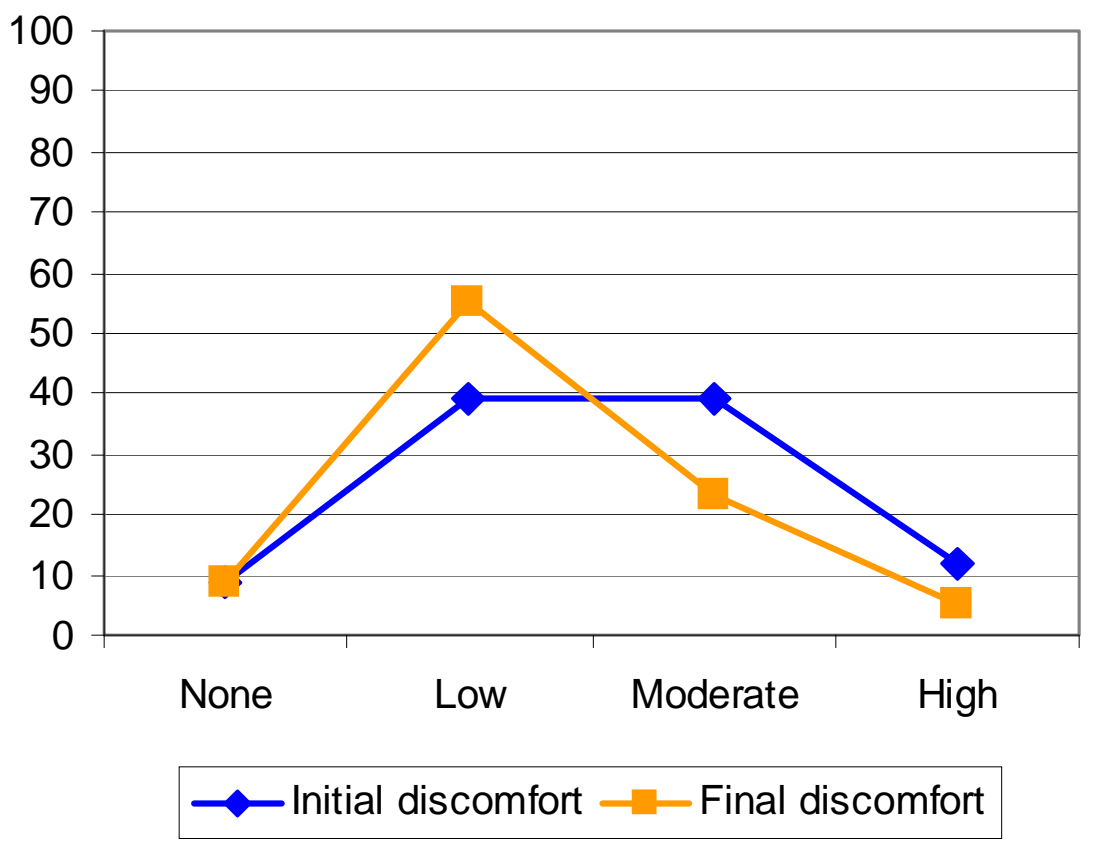

\section{Graphic 2. Perception of initial discomfort compared to the distress experienced at the end of the bad news communication process}

express his/her emotions and the $37.8 \%$ usually do it; $53.7 \%$ usually identify emotions that require immediate attention, whereas 28\% always do it; $41.5 \%$ usually make sure that the patient receives emotional support and $29.3 \%$ and $3.7 \%$ sometimes and never, respectively, think about it. Of the participants, 53.7\% usually avoid the use of words like «cancer», «death», «terminal condition», and the like, and 31\% always do it. High percentages $(68.3 \%)$ of the participants always devise a joint action plan with the patient (Table 2).

Emotions. As far as the doctor's emotions, it was found that $32.9 \%$ never identify their own emotions when communicating bad news and $35.4 \%$ sometimes do it. A sense of sadness is usually or always found in 
Table 3

Doctors' training to communicate of bad news

\begin{tabular}{|c|c|c|c|c|c|c|c|}
\hline \multirow[t]{2}{*}{ Variable } & \multicolumn{2}{|c|}{ None } & \multicolumn{2}{|c|}{ Low } & \multicolumn{2}{|c|}{ Moderate } & High \\
\hline & \multicolumn{2}{|c|}{$\mathrm{N}(\%)$} & \multicolumn{2}{|c|}{ N (\%) } & \multicolumn{2}{|c|}{ N (\%) } & N (\%) \\
\hline Knows clinical protocols to disclose bad news & \multicolumn{2}{|c|}{$34(41.5)$} & \multicolumn{2}{|c|}{$18(22.0)$} & \multicolumn{2}{|c|}{$24(29.3)$} & $6(7.3)$ \\
\hline Training in communication skills to deliver bad news & \multicolumn{2}{|c|}{$30(36.6)$} & \multicolumn{2}{|c|}{$30(36.6)$} & \multicolumn{2}{|c|}{$18(22.0)$} & $4(4.9)$ \\
\hline Training in emotional crisis intervention & \multicolumn{2}{|c|}{$52(63.4)$} & \multicolumn{2}{|c|}{$16(19.5)$} & \multicolumn{2}{|c|}{$11(13.4)$} & $3(3.7)$ \\
\hline Would like to be trained on this topic & \multicolumn{2}{|c|}{$1(1.2)$} & \multicolumn{2}{|c|}{$9(11.0)$} & \multicolumn{2}{|c|}{$25(30.5)$} & $47(57.3)$ \\
\hline \multicolumn{8}{|c|}{$\begin{array}{c}\text { Table } 4 \\
\text { Use of organizational resources to communicate bad news }\end{array}$} \\
\hline \multirow[t]{2}{*}{ Variable } & \multirow{2}{*}{$\begin{array}{l}\text { Never } \\
\mathrm{N}(\%)\end{array}$} & \multicolumn{2}{|c|}{ Sometimes } & \multicolumn{2}{|c|}{ Usually } & \multirow{2}{*}{$\begin{array}{c}\text { Always } \\
\text { N (\%) }\end{array}$} & \multirow{2}{*}{$\frac{N^{\circ} \text { data }}{\mathbf{N}(\%)}$} \\
\hline & & $\mathbf{N}($ & & $\mathbf{N}(\mathbf{c}$ & & & \\
\hline Has enough time & $4(4.9)$ & 33( & & $34(<$ & & $11(13.4)$ & - \\
\hline Has adequate space available & $3(3.7)$ & 22( & & $41(5$ & & $16(19.5)$ & - \\
\hline Access to interdisciplinary support & $3(3.7)$ & 16( & & $23(2$ & & $40(48.8)$ & - \\
\hline Frequency of using interdisciplinary support & $4(4.9)$ & 42( & & $25(3$ & & $8(9.8)$ & $3(3.7)$ \\
\hline $\begin{array}{l}\text { Doctors have access to support for dealing with } \\
\text { emotions triggered by the process }\end{array}$ & $14(17.1)$ & 19( & & $18(2$ & & $30(36.6)$ & $1(1.2)$ \\
\hline
\end{tabular}

$61 \%$ of the participants, $39.1 \%$ always or usually feel anxious during the process of breaking bad news; $30.5 \%$ always or usually feel helpless; $28.1 \%$ usually and always feel frustration; $4.9 \%$ usually feel fear for an unexpected patient's reaction and only $1.2 \%$ usually show guilt (Graphic 1 ).

Final discomfort. Of the respondents, 56.1\% and $23.2 \%$ show little and moderate discomfort, respectively, at the end of the meeting with the patient; only $8.5 \%$ do not evidence it (Graphic 2).

Training. Of the participants, $41.5 \%$ do not know about bad news communication protocols; only $7.3 \%$ think that they are well-informed about aspects needed to be considered when breaking bad news; $73.2 \%$ have received none or hardly any training on communication skills to disclose bad news to the patients. Of the doctors, $63.4 \%$ do not have any training on emotional crisis intervention followed by $19.5 \%$ who have slight training; $57.3 \%$ are willing to be trained on communication skills for the disclosure of bad news and $30.5 \%$ have a moderate desire to receive training (Table 3 ).

Organizational resources. A high percentage of doctors (40.2\% and $41.5 \%)$ respectively, deem that sometimes and usually they have enough time available in the institution where they work to communicate bad news to their patients. Of the doctors, $69.5 \%$ usually and always consider that the space is adequate to communicate the event. As far as the access to interdisciplinary support to facilitate and guide the patient along the process, $76.8 \%$ think that it is always or usually available. However, only $40.3 \%$ state that they always or usually use it. Of the study participants, $68.6 \%$ assert that they always or usually have support available in the institution where they work to deal with emotions triggered by the communication of bad news to the patients (Table 4).

\section{DISCUSSION}

The study results show that doctors use tools that facilitate the communication of bad news to the patients and their relatives, such as: being familiar with the patients' medical history, ensure that there is enough time, know the patient's caregivers and/or relatives, 
determine the patient's level of knowledge about his/her condition. In addition they use non-technical words, give information in small pieces, assess the patient's understanding of the information they are given, together they devise a joint action plan, among others.

On the other hand, factors that might be emotional barriers for the communication process, particularly those related to the identification of their own emotions, were observed. It may happen because of the limited training reported by the research participant doctors (a high percentage of them reports having received insufficient training in communication skills and emotional crisis intervention). As a consequence, the doctor avoids involving emotionally when he/she communicates bad news, and he/she may even deny his/her own feelings. This agrees with several studies approach which confirms that adequate formal training in how to discuss bad news with patients and their families is offered to few of doctors ${ }^{11-13}$. According to the information reported in the literature, poor training contributes, to a great extent, to the «burn-out» syndrome (professional emotional weakening or exhaustion) characterized by de-personalization and emotional exhaustion ${ }^{14,15}$.

Although the study participants are not aware of their emotions throughout the process of communicating bad news, they manage to identify theirpatients' emotions and allow them to express their feelings. These results oppose to Lee et al. ${ }^{7}$ approach where physicians are not good at detecting patient distress during bad news encounters. Yet, it is remarkable that the study doctors who claim having observed the patient's need for immediate emotional attention do not use psycho-social support services, though a great percentage of doctors report that these services are available in the institutions where they work. These results concur with Burton and Parker ${ }^{16}$ and with Girgis et al. ${ }^{17}$ It may be that due to the different doctors' beliefs that providing psycho-social support and monitoring are rated as not very important by patients in their treatment and/or recovery, they underestimate the benefits of an emotional intervention ${ }^{18}$.

It is also relevant to examine the doctors' behavior when they deal with patients' emotions that require immediate attention during consultation, since the limited formal training in communication skills may be related to the difficulty in recognizing the emotions caused by the delivery of bad news.

It was found that the main emotions experienced by doctors in the communication of bad news are sadness to think about what awaits for the patient in the future and anxiety to avoid increasing patient's suffering when they communicate the bad news; not many participants experience fear. This differs from Dosanjh et al. ${ }^{19}$ findings which state that the main feeling reported by doctors when they have to communicate bad news is to be unprepared.

Generally, it is obvious that delivering bad news causes distress in the doctors, both at the beginning and at the end of the process; this feeling changes during the process. This is similar to Ptacek and Eberhardt finding ${ }^{5}$, who state that doctors experience more stress before meeting the patient than at the end of the encounter.

Consequently, it is necessary to implement training programs that offer specific communication tools to deal with the patients and doctors' emotional issues in order to facilitate the process of delivering bad news. Similarly and as it was described before, this type of training could affect the patient's well-being directly and indirectly, as far as his/her emotional state, symptoms control, treatment adherence, better therapeutic results, among others.

To interpret the study results, it is important to consider the study limitations due to the fact that data were collected through a self-administered instrument in an unreal time. Therefore, answers can be determined by the retrospective doctor's perception and by each participant's level of honesty. It is recommended to use qualitative methodologies in subsequent studies focused on observation (through video recording of real-life situations) and to interview participants deeply, which allow gathering more detailed data or information about the process of communicating bad news to the patient.

\section{ACKNOWLEDGMENT}

We thank the Hospital Pablo Tobón Uribe for its participation in the study.

\section{REFERENCES}

1. Alves de Lima A.E. ¿Cómo comunicar malas noticias a nuestros pacientes y no morir en el intento? Rev Argent Cardiol. 2003; 71: $217-20$.

2. Fallowfield L. Giving sad and bad news. Lancet. 1993; 341: 476-8.

3. Simpson M, Buckman R, Stewart M, Maguire P, Lipkin M, Novack D, et al. Doctor patient communication: the Toronto consensus statement. BMJ. 1991; 303: 1305-7. 
4. Astudillo AW, Da Rocha AC. Alivio de las situaciones difíciles y del sufrimiento en la terminalidad. San Sebastián: SOVPAL; 2005.

5. Ptacek JT, Eberhardt TL. Breaking bad news: a review of the literature. JAMA. 1996; 276: 496-502.

6. Buckman R. Breaking bad news-why is it still so difficult? $\mathrm{Br}$ Med J. 1984; 288: 1597-9.

7. Lee SJ, Back AL, Block SD, Stewart SK. Haematology. Am Soc Hematol Educ Program. 2002: 291: 464-83.

8. Astudillo W, Mendinueta C, Astudillo E. Cuidados del enfermo en fase terminal y atención de su familia. Pamplona: Universidad de Navarra; 1995. p.43.

9. Soriano J, Norat T, Arrébola JA, Fleites G. Algunas consideraciones éticas en torno al cáncer. En: Acosta JR (ed.) Bioética desde una perspectiva cubana. La Habana: Centro Félix Varela; 1997. pp. 165-72.

10. Radovsky SS. Bearing the news. NEngl J Med. 1985; 313: 5868.

11. Eggly S, Alfonso N, Rojas G, Baker M, Cardozo L, Robertson RS. An assessment of residents' competence in the delivery of bad news to patients. Acad Med. 1997; 72: 397-9.

12. Reynolds $M$. No news is bad news: patients' views about communication in hospital. Br Med J. 1978; 1: 1673-6.

13. Oelz O. Truth disclosure in physicians' dialogue: compassionate lie or merciless statistics? Praxis. 1996; 85: 440-4.

14. Mueller PS. The SPIKES approach can make this difficult task easier. Postgrad Med. 2003; 113: 23.

15. Fallowfield L, Jenkins V. Communicating sad, bad, and difficult news in medicine. Lancet. 2004; 363: 312-9.

16. Burton MV, Parker RW. Psychological aspects of cancer surgery: surgeons' attitudes and opinions. Psychooncology. 1997; 6: 47-64.

17. Girgis A, Sanson-Fisher RW, McCarthy WH. Communicating with patients: surgeons' perceptions of their skills and need for training. Aust N Z J Surg. 1997; 67: 775-80.

18. Schofield P, Carey M, Bonevski B, Sanson-Fisher R. Barriers to the provision of evidence-based psychosocial care in oncology. Psychooncology. 2006; 15: 863-72.

19. Dosanjh S, Barnes J, Bhandari M. Barriers to breaking bad news among medical and surgical residents. Med Educ. 2001;35: 18890 . 